\title{
ANALISA EFESIENSI KETEL UAP PADA UNIT 2 PLTU 2 BANTEN KAPASITAS 300 MW
}

\author{
Dian Jaelani \\ Sony Sukmara
}

\begin{abstract}
ABSTRAK
Boiler atau ketel uap adalah sebuah bejana tertutup yang berfungsi sebagai ruang pembakaran ini merupakan kombinasi antara sistem dan peralatan yang dipakai untuk merubah energy kimia yaitu bahan bakar menjadi energi termal dan pemindahan energy termal yang dihasilkan itu ke fluida kerja sehingga berubah dari air menjadi uap

Sebuah ketel uap dioperasikan selama 5 tahun maka akan diperkirakan akan terjadi penurunan unjuk kerja ketel uap tersebut. Untuk mengetahui berapa penurunannya maka dilakukan perhitungan dengan metode input - output untuk mengetahui berapa efesiensi ketel uap saat ini dibandingkan dengan hasil komisioning.

Ternyata dari hasil perhitungan dapat diketahui bahwa keadaan ketel uap masih memadai untuk beroperasi, walaupun banyak kekurangan yang terdapat didalam ketel uap tersebut. Hasil perhitungan dengan metode input - output ketel uap ketika komisioning memiliki efisiensi 90,5\%, sedangkan Mei 2016 memiliki efisiensi $83,4 \%$.
\end{abstract}

Kata Kuci : Ketel uap, Metode Input Output, Efesiensi Komisioning, Efesiensi Mei 2016.

\begin{abstract}
Boiler is a closed vessel that serves as the combustion chamber is a combination of systems and equipment used to convert chemical energy of fuel into thermal energy and transfer of thermal energy generated so that the working fluid changes from water to steam
\end{abstract}

A natural circulation type boiler is operated for 5 years it will be expected to decline in the performance of these boilers. To find out how much the reduction is carried out some calculations by method of input - output to find out how the effeciency of the boiler is now compared with the results of commisioning.

Apparently from the calculation can be seen that the situation is still adequate boiler to operate, although many shortcomings inherent in these boilers. The results computed when commisioning has an efficiency $90.5 \%$ and May 2016 has an effeciency $83.4 \%$.

Key word's : The boiler, Method of input-output, The efficiency of commissioning, The efficiency of May 2016

\section{Rumusan Pokok Masalah}

Berdasarkan latar belakang masalah diatas maka penulis melakukan identifikasi masalah sebagai berikut :

1. Apakah ada penurunan nilai efesiensi ketel uap pada saat komisioning dibandingkan sekarang?

2. Apa yang menjadi pengaruh turunnya nilai efesiensi ketel uap di PLTU 2 Banten Unit 2 ?

\section{Tujuan}

Tujuan penelitian ini Adalah :

1. Menghitung efisiensi ketel uap/boiler pada Pembangkit Listrik Tenaga Uap (PLTU) Jawa Bali, Unit Pembangkit Labuan 2 Banten.

2. Meyimpulkan dan memberikan saran saran untuk meningkatkan kinerja ketel uap tersebut pada khususnya dan operasional pabrik pada umumnya.

\section{Batasan Masalah}

Penulis menentukan batasan masalah yang akan dibahas agar 
mempermudah dan tidak terlalu dalam pembahasannya yaitu :

1. Analisa tentang efisiensi energi ketel uap. Analisa perhitungan diambil pada

saat beban tinggi dengan menggunakan metode perhitungan metode input output

\section{Siklus PLTU 2 Labuan}

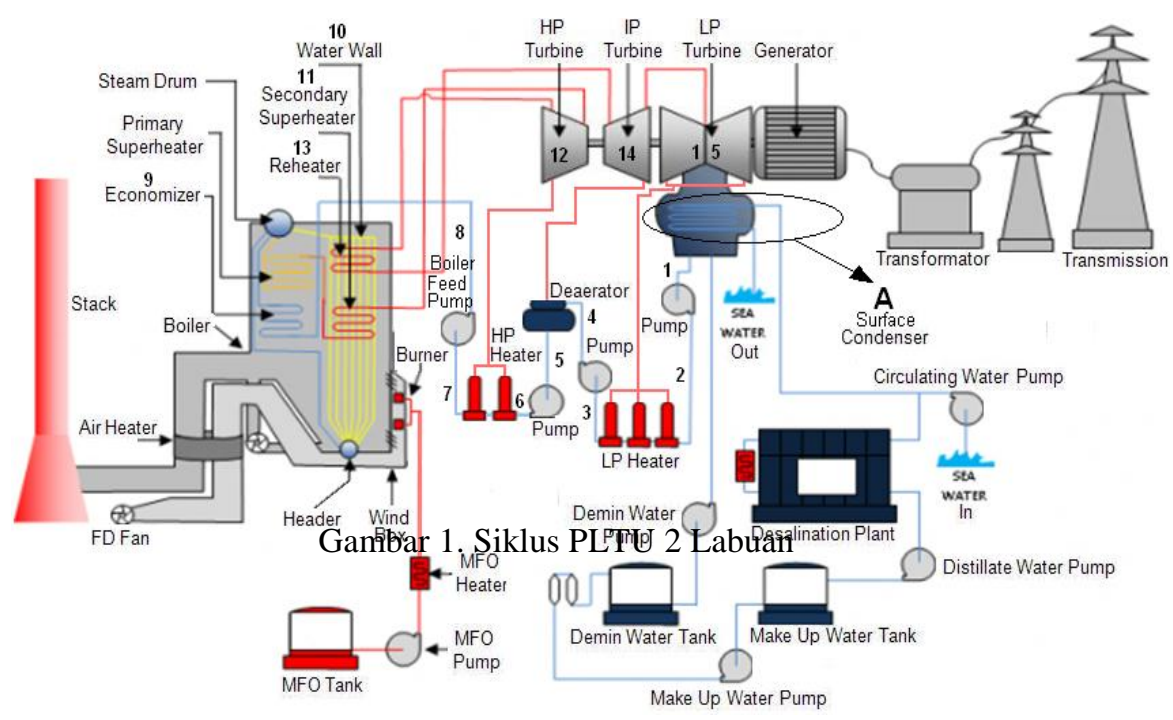

Skema proses berubah air menjadi uap panas lanjut bertekanan tinggi sehingga dapat menggerakkan turbin generator yang menghasilkan energi listrik.

\section{Energi Yang Dihasilkan PLTU Labuan}

Generator atau alternator merupakan komponen utama PLTU yang berfungsi untuk mengubah energi mekanik menjadi energi listrik. Kapasitas generator PLTU 2 Labuan 2 X 300 MW. berikut :

Adapun spesifikasi generator PLTU labuan adalah seperti terlihat pada tabel 1

Tabel 1. Basic Spesification Generator [10]

\begin{tabular}{|l|c|}
\hline Type & QFSN-300-2-20B \\
\hline Maximum continnuous output & $300 \mathrm{MW}(353 \mathrm{MVA})$ \\
\hline Rated Voltage & $10.732 \mathrm{kA}$ \\
\hline Rated current & 0.85 \\
\hline Rated power factor & $50 \mathrm{~Hz}$ \\
\hline Rated frequency & $3000 \mathrm{rpm}$ \\
\hline Rated speed & 3 \\
\hline Number of phases & $\mathrm{Y}$ \\
\hline Stator winding connection & \\
\hline
\end{tabular}




\section{Rumus Perhitungan Efesiensi Boiler Dengan Metode Input Output}

1. Panas yang masuk pada Main Steam

$\mathrm{Q}_{l}=\mathrm{W}_{1}\left(\mathrm{~h}_{1}-\mathrm{h}_{2}\right)$

Keterangan :

$\mathrm{W}_{1}=$ Aliran uap yang

dihasilkan

$\mathrm{h}_{1}=$ Enthalpi uap superheater outlet

$\mathrm{h}_{2}=$ Enthalpi feedwater masuk economizer

2. Panas yang masuk pada Superheater Spray Water

$\mathrm{Q}_{2}=\mathrm{W}_{2}\left(\mathrm{~h}_{1}-\mathrm{h}_{3}\right)$

3. Panas yang masuk pada aliran Reheat

$\mathrm{Q}_{3}=\mathrm{W}_{3}\left(\mathrm{~h}_{4}-\mathrm{h}_{5}\right)$

Keterangan :

$\mathrm{W}_{3}=$ Aliran reheater steam

$\mathrm{h}_{4}=$ Enthalpi uap pada reheat outlet

$\mathrm{h}_{5}=$ Enthalpi uap pada reheat inlet

Panas yang masuk pada Reheat Spray Water

$\mathrm{Q}_{4}=\mathrm{W}_{4}\left(\mathrm{~h}_{4}-\mathrm{h}_{6}\right)$

$\mathrm{h}_{6}=$ Enthalpi aliran reheater

spray water

4. Total panas yang masuk pada feedwater adalah :

$\mathrm{Q}_{\text {total }}=\mathrm{Q}_{1}+\mathrm{Q}_{2}+\mathrm{Q}_{3}+\mathrm{Q}_{4}$
5. Total panas input ke Boiler adalah :

$$
\begin{aligned}
& \mathrm{B}=\left(H_{f} x W_{f e}\right) \\
& \mathrm{H}_{\mathrm{f}}=\text { Nilai kalori batubara } \\
& \mathrm{W}_{\mathrm{FE}}=\text { Laju aliran bahan } \\
& \text { bakar }
\end{aligned}
$$

Adapun formulasi untuk metode input - output adalah

$$
\eta_{\mathrm{g}}=\frac{Q_{\text {total }}}{\left(H_{f} x W_{f e}\right)} \times 100 \%
$$

\section{Spesifikasi Ketel Uap}

Data teknis dari ketel uap tipe DG1025/17.4 Sub Critical Natural Circulation Boiler (boiler jenis sirkulasi alamiah) ini adalah :

Pabrik pembuat : Dongfang

Boiler Group Co.Ltd

Type

DG1025/17.4 Sub Critical Natural

Circulation

$$
\text { Boiler }
$$

Kapasitas uap

ton/jam

Tekanan Kerja

$\mathrm{Kg} / \mathrm{cm}^{2}$

Suhu

Jumlah burner

buah

Bahan bakar utama

Batubara

Tinggi cerobong : 215 meter 


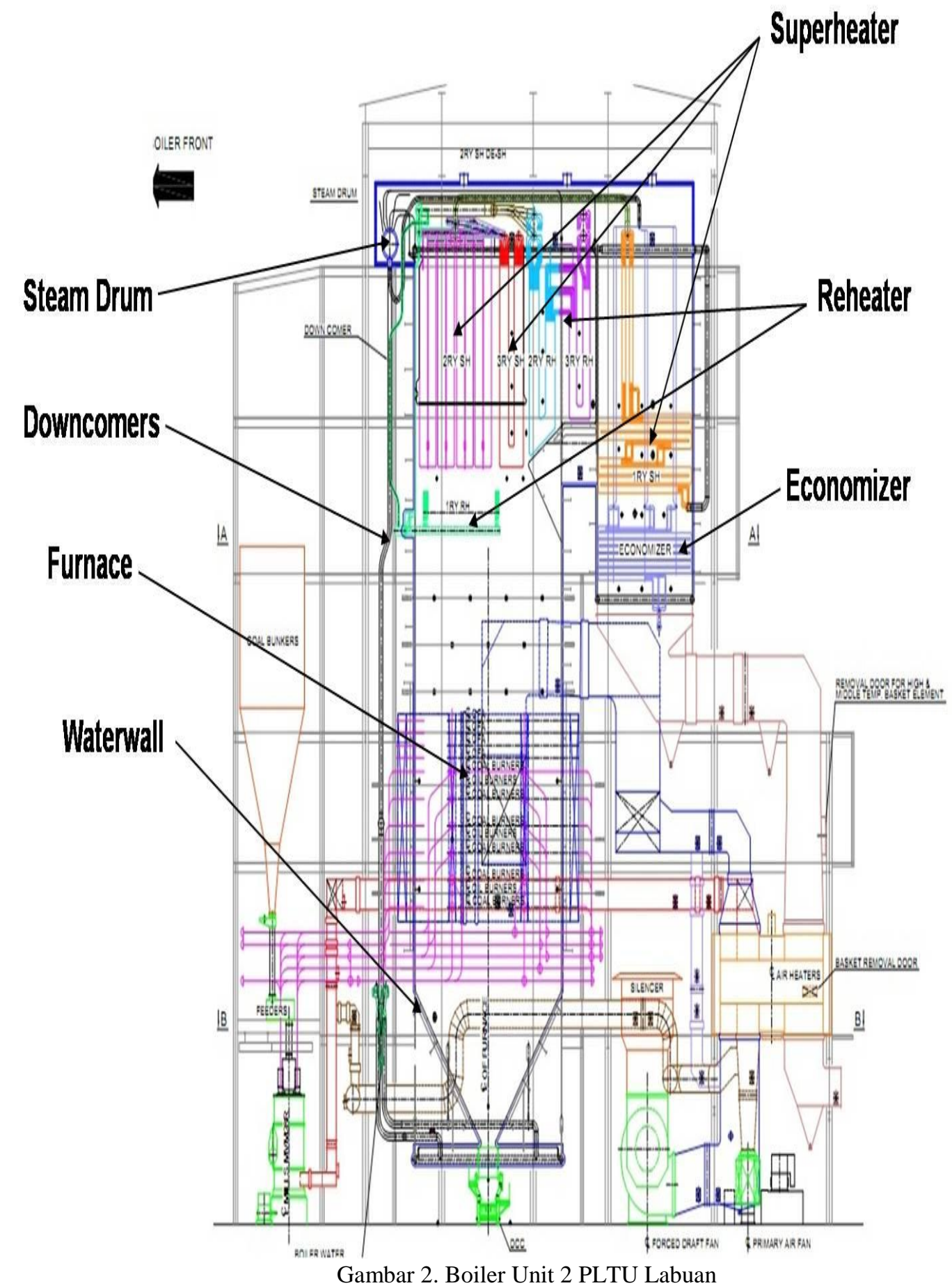




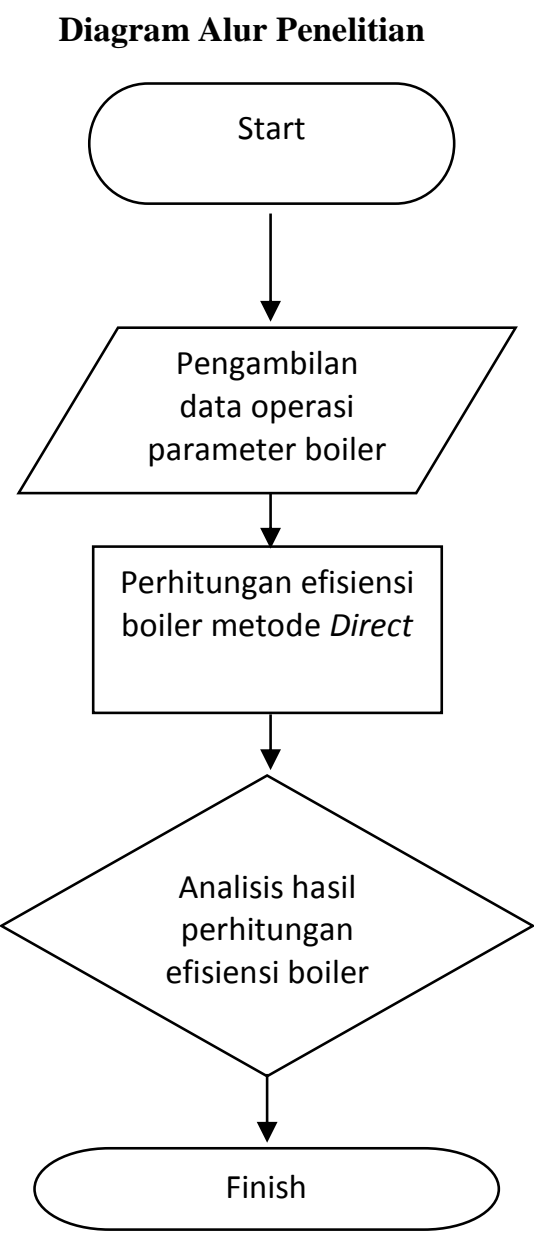

Gambar 3. Diagram Alur Penelitian

\section{PERHITUNGAN DAN ANALISA}

Dari data operasi dan spesifikasi teknik, diketahui :

Tabel 2. Data Operasional Komisioning

\begin{tabular}{|c|l|c|c|}
\hline No & \multicolumn{1}{|c|}{ Item } & Satuan & Ouput \\
\hline 1 & Generator Output & $\mathrm{MW}$ & 300 \\
\hline 2 & Main Steam Flow & $\mathrm{kg} / \mathrm{h}$ & 971429 \\
\hline 3 & Feed Water Flow & $\mathrm{kg} / \mathrm{h}$ & 956710 \\
\hline 4 & Hot Reheat Steam Flow & $\mathrm{kg} / \mathrm{h}$ & 813037.199 \\
\hline 5 & Cold Reheat Steam Flow & $\mathrm{kg} / \mathrm{h}$ & 813.07 \\
\hline
\end{tabular}




\begin{tabular}{|c|c|c|c|}
\hline 6 & Superheater Spray Water Flow & $\mathrm{kg} / \mathrm{h}$ & 17380.705 \\
\hline 7 & Reheater Spray Water Flow & $\mathrm{kg} / \mathrm{h}$ & 0 \\
\hline 8 & Main Steam Pressure & Bar & 164.6 \\
\hline 9 & Main Steam Temperature & ${ }^{\circ} \mathrm{C}$ & 537.01 \\
\hline 10 & Feed Water Pressure & Bar & 186.6 \\
\hline 11 & Feed Water Temperature & ${ }^{\circ} \mathrm{C}$ & 274.17 \\
\hline 12 & Hot Reheat Pressure & Bar & 32.84 \\
\hline 13 & Hot Reheat Temperature & ${ }^{\circ} \mathrm{C}$ & 536.55 \\
\hline 14 & Cold Reheat Pressure & Bar & 36.57 \\
\hline 15 & Cold Reheat Temperature & ${ }^{\circ} \mathrm{C}$ & 326.84 \\
\hline 16 & Superheater Spray Water Pressure & Mpa & 191.5 \\
\hline 17 & Superheater Spray Water Temperature & ${ }^{\circ} \mathrm{C}$ & 178.00 \\
\hline 18 & Reheat Spray Water Pressure & Mpa & 105.1 \\
\hline 19 & Reheat Spray Water Temperature & ${ }^{\circ} \mathrm{C}$ & 165.6 \\
\hline
\end{tabular}

\section{Data Operasional Mei 2016}

Dari data operasi dan spesifikasi teknik, diketahui :

Tabel 3. Data Operasional Mei 2016

\begin{tabular}{|c|l|c|c|}
\hline No & \multicolumn{1}{|c|}{ Item } & Satuan & Ouput \\
\hline 1 & Generator Output & $\mathrm{MW}$ & 300 \\
\hline 2 & Main Steam Flow & $\mathrm{kg} / \mathrm{h}$ & 935187.43 \\
\hline 3 & Feed Water Flow & $\mathrm{kg} / \mathrm{h}$ & 872260 \\
\hline 4 & Hot Reheat Steam Flow & $\mathrm{kg} / \mathrm{h}$ & 738960 \\
\hline 5 & Cold Reheat Steam Flow & $\mathrm{kg} / \mathrm{h}$ & 669580 \\
\hline 6 & Superheater Spray Water Flow & $\mathrm{kg} / \mathrm{h}$ & 62.92 \\
\hline 7 & Reheater Spray Water Flow & $\mathrm{kg} / \mathrm{h}$ & 69.38 \\
\hline 8 & Main Steam Pressure & $\mathrm{Bar}$ & 152.3 \\
\hline 9 & Main Steam Temperature & ${ }^{\circ} \mathrm{C}$ & 536.64 \\
\hline
\end{tabular}




\begin{tabular}{|c|l|c|c|}
\hline 10 & Feed Water Pressure & Bar & 170.8 \\
\hline 11 & Feed Water Temperature & ${ }^{\circ} \mathrm{C}$ & 274.87 \\
\hline 12 & Hot Reheat Pressure & Bar & 34.25 \\
\hline 13 & Hot Reheat Temperature & ${ }^{\circ} \mathrm{C}$ & 535.58 \\
\hline 14 & Cold Reheat Pressure & Bar & 37.21 \\
\hline 15 & Cold Reheat Temperature & ${ }^{\circ} \mathrm{C}$ & 346.9 \\
\hline 16 & Superheater Spray Water Pressure & $\mathrm{Mpa}$ & 174.58 \\
\hline 17 & Superheater Spray Water Temperature & ${ }^{\circ} \mathrm{C}$ & 179.90 \\
& & & \\
\hline 18 & Reheat Spray Water Pressure & $\mathrm{Mpa}$ & 89.16 \\
\hline 19 & Reheat Spray Water Temperature & ${ }^{\circ} \mathrm{C}$ & 178.70 \\
& & & \\
\hline
\end{tabular}

Hasil Perhitungan Efesiensi Hasil Komisioning

Panas yang masuk pada Superheater

$$
\mathrm{Q}_{1}=2129275225 \mathrm{~kJ} / \mathrm{jam}
$$

Panas yang masuk pada Superheater Spray Water

$$
\mathrm{Q}_{2}=45959190 \mathrm{~kJ} / \mathrm{jam}
$$

Panas yang masuk pada Reheat

$$
\mathrm{Q}_{3}=400859762 \mathrm{~kJ} / \mathrm{jam}
$$

Panas yang masuk pada Reheat Spray Water

$$
\mathrm{Q}_{4}=0 \mathrm{~kJ} / \mathrm{jam}
$$

Total panas yang output pada Boiler adalah :

$\mathrm{Q}_{4}$

$$
\mathrm{Q}_{\text {total }}=\mathrm{Q}_{1}+\mathrm{Q}_{2}+\mathrm{Q}_{3}+
$$

$$
=2576094177 \mathrm{~kJ} / \mathrm{jam}
$$

Total panas input ke Boiler adalah :

$$
\begin{aligned}
& \mathrm{B}=\left(H_{f} x W_{f e}\right) \\
& \mathrm{B}=(17584 \times 161770)= \\
& 2844563680 \mathrm{kj} / \mathrm{jam}
\end{aligned}
$$

Menghitung efisiensi dengan metode Input - Output

$$
\begin{gathered}
\eta= \\
\frac{Q_{\text {total }}}{\left(H_{f} x W_{f e}\right)} \times 100 \% \\
\eta=90.5 \%
\end{gathered}
$$

Perhitungan dengan Metode Input Output Mei 2016

Panas yang masuk pada Superheater

$$
\mathrm{Q}_{1}=2058478460 \mathrm{~kJ} / \mathrm{jam}
$$

Panas yang masuk pada Superheater Spray Water

$$
\mathrm{Q}_{2}=166675189.7 \mathrm{~kJ} / \mathrm{jam}
$$

Panas yang masuk pada Reheat

$$
\mathrm{Q}_{3}=325711399.20 \mathrm{~kJ} / \mathrm{jam}
$$

Panas yang masuk pada Reheat Spray Water

$$
\mathrm{Q}_{4}=192294926.22 \mathrm{~kJ} / \mathrm{jam}
$$

Total panas yang output pada Boiler adalah :

$$
\begin{aligned}
& \mathrm{Q}_{\text {total }}=\mathrm{Q}_{1}+\mathrm{Q}_{2}+\mathrm{Q}_{3}+\mathrm{Q}_{4} \\
& \quad=2743159975 \\
& \mathrm{~kJ} / \mathrm{jam}
\end{aligned}
$$

Total panas input ke Boiler adalah :

$$
\begin{aligned}
\mathrm{B} & =\left(H_{f} x W_{f e}\right) \\
\mathrm{B} & =(19403.35 \mathrm{x} \\
169514.71) & =3289153248 \mathrm{kj} / \mathrm{jam}
\end{aligned}
$$




\section{Menghitung efisiensi dengan metode Input - Output}

$$
\begin{gathered}
\eta= \\
\frac{Q_{\text {total }}}{\left(H_{f} x W_{f e}\right)} \times 100 \%
\end{gathered}
$$

$$
\eta=83.4 \%
$$

\section{KESIMPULAN DAN SARAN}

\section{Kesimpulan}

Analisis kinerja boiler dilakukan guna mengetahui tingkat efisiensi serta peluang peningkatan efisiensi yang mungkin dilakukan. Analisis efisiensi boiler dilakukan dengan metode langsung (direct Metode) memperhitungkan input dan output. Untuk melakukan analisa kinerja boiler dengan metoda tidak langsung dibutuhkan data ultimate analisis main steam, data analisis coal flow, serta beberapa data penunjang lainnya. Hasil perhitungan kinerja boiler unit 2 PLTU 2 Banten-Labuan dengan menggunakan metoda langsung (direct Metode ), didapatkan hasil nilai efisiensi sebesar 83,4 \%, nilai efisiensi ini jika dibandingkan dengan inspeksi komisioning sebesar $90,5 \%$ memiliki perbedaan yaitu sebesar $7,1 \%$.

\section{Saran}

Kinerja boiler dapat ditingkatkan dengan melihat peluang-peluang peningkatan efisiensi yang mungkin dilakukan dengan mengacu pada hasil analisis, seperti:

1. Perlu dilakukan pengecekan pipapipa didalam boiler saat Overhaul.

2. Perbaikan komponen-komponen yang rusak pada peralatan sootblower.

3. Pengaturan tielting diusahakan di $50 \%$ pada saat operasi.

\section{DAFTAR PUSTAKA}

[1] Djokosetyahardjo, M.J., 1989. Ketel Uap, Jakarta, Pradnya Paramita
[2] El - Wakil, M. M, 1984.Power Plant Technology, first edition, Mc Graw Hill, Inc, USA.

[3] Basori , Hasan, 2011. “ Prinsip kerja PLTU 2 Labuan ", Banten : PLTU 2 Labuan.

[4] Mustafa, Bustani, 2004: Dasar Termodinamika Tehnik, Jakarta : Univ. Trisakti.

[5] PLN, 1982, Performance Test Procedure, Jakarta.

[6] PTC 4.1, ASME, 1964. Steam Generating Unit, The American Society of Mechanical Engineers, USA.

[7] Robert H. Perry and Don W. Green, 1997 : PERRY'S CHEMICAL ENGINEER'S HANDBOOK, seventh edition, Mc Graw - Hill, Inc, USA.

[8] Teguh P, Bambang, Konservasi Energi Di Boiler, Serpong, Balai Termodinamika, Motor dan Propulasi BPPT - Puspitek.

[9] www.energyefficiencyasia.org. Pedoman Efisiensi Energi untuk Industri di Asia. 10 November 2010

[10] Dongfang, 2010, Manual Book power plant, Banten. 